\title{
MCM family in HCC: MCM6 indicates adverse tumor features and poor outcomes and promotes $\mathrm{S} / \mathrm{G} 2$ cell cycle progression
}

\author{
Zhikun Liu' ${ }^{1,2}$, Jie Li ${ }^{2}$, Jun Chen ${ }^{1,2}$, Qiaonan Shan², Haojiang Dai ${ }^{2}$, Haiyang Xie ${ }^{2}$, Lin Zhou², Xiao Xu ${ }^{1,2,3^{*}}$ \\ and Shusen Zheng ${ }^{1,2,3^{*}}$
}

\begin{abstract}
Background: Minichromosome Maintenance family (MCMs), as replication licensing factors, is involved in the pathogenesis of tumors. Here, we investigated the expression of MCMs and their values in hepatocellular carcinoma (HCC).

Methods: MCMs were analyzed in 105 samples including normal livers $(n=15)$, cirrhotic livers $(n=40)$, HCC $(n=50)$ using quantitative polymerase chain reaction (qPCR) (Cohort 1). Significantly up-regulated MCMs were verified in 102 HCC and matched peritumoral livers using PCR (Cohort 2), and the correlations with clinical features and outcomes were determined. In addition, the focused MCMs were analyzed in parallel immunohistochemistry of 345 samples on spectrum of hepatocarcinogenesis (Cohort 3) and queried for the potential specific role in cell cycle.

Results: MCM2-7, MCM8 and MCM10 was significantly up-regulated in HCC in Cohort 1. In Cohort 2, overexpression of MCM2-7, MCM8 and MCM10 was verified and significantly correlated with each other. Elevated MCM2, MCM6 and MCM7 were associated with adverse tumor features and poorer outcomes. In Cohort 3, MCM6 exhibited superior HCC diagnostic performance compared with MCM2 and MCM7 (AUC: 0.896 vs. 0.675 and $0.771, P<0.01$ ). Additionally, MCM6 other than MCM2 and MCM7 independently predicted poorer survival in 175 HCC patients. Furthermore, knockdown of MCM6 caused a delay in S/G2-phase progression as evidenced by down-regulation of CDK2, CDK4, CyclinA, CyclinB1, CyclinD1, and CyclinE in HCC cells.

Conclusions: We analyze MCMs mRNA and protein levels in tissue samples during hepatocarcinogenesis. MCM6 is identified as a driver of S/G2 cell cycle progression and a potential diagnostic and prognostic marker in HCC.
\end{abstract}

Keywords: Hepatocarcinogenesis, HCC, MCMs, MCM6

\section{Background}

Hepatocarcinogenesis is a typical stepwise process evolving from normal hepatocytes through chronic cirrhosis to hepatocellular carcinoma (HCC) $[1,2]$. In China, there are 93 million hepatitis $\mathrm{B}$ virus (HBV) carriers which is $7.2 \%$ of the entire population, and HCC patients account for over $55 \%$ of new HCC cases worldwide [3, 4]. Sustained inflammation caused by HBV infection contributes to the majority etiology of HCC, and thus presents the opportunity to use liver samples

\footnotetext{
* Correspondence: zjxu@zju.edu.cn; zhengshusen@zju.edu.cn

'Division of Hepatobiliary and Pancreatic Surgery, Department of Surgery, First Affiliated Hospital, Zhejiang University School of Medicine, Hangzhou, China

Full list of author information is available at the end of the article
}

from different stages of HBV-triggered disease to study the interesting genes or proteins suspected to be involved in hepatocarcinogenesis.

DNA replication is the scientific interest in studying the development and progression of tumor. The minichromosome maintenance family (MCMs) plays a central role in the replication, as replicative DNA helicase, and forms a hexameric ring-shaped complex around DNA. MCM proteins were first recognized in the yeast Saccharomyces cerevisiae and are essential for DNA replication in all eukaryotic cells, playing an important role in limiting replication in each cell cycle [5]. At least 10 homologues have been characterized in humans. Among these, the MCM2-7 complex participates in the pre-replication complex formation and exhibits helicase activity which 
makes DNA unwind, and resulting in recruitment of DNA polymerases and initiation of DNA replication and elongation $[6,7]$. MCM8 is associated with chromosomal instability [8]. MCM10 mediates the interaction between RECQL4 and the MCM2-7 complex during DNA replication [9]. The twisted and tilted single hexamer shape of MCMs suggests a concerted mechanism that requires the structural deformation of the intervening DNA [10]. MCMs are essential for DNA replication in dividing cells and are lost in quiescence.

MCMs are candidate markers for cell proliferation, and increased levels of MCMs indicate proliferation of malignant cells. An increasing body of evidence suggests that MCMs predict tumor progression and prognosis. MCMs have been reported to be abnormally expressed in multiple malignancies including cervical cancer [11], breast cancer [12], and human gliomas [13]. Some MCMs have been found to be associated with disease prognosis. MCM2 is a useful marker in screening for cervical carcinoma [14], oral squamous cell carcinoma [15] and medulloblastoma [16], and it serves as a therapeutic target of the drug lovastatin in non-small cell lung carcinomas [17]. MCM3 may be a better marker than Ki-67 for the evaluation of dysplastic oral lesions [18]. A mutation of MCM4 is detected in skin cancer cells, which affects the DNA helicase activity of the MCM2-7 complex [19]. MCM5 is associated with breast cancer prognosis [20]. MCM7 contributes to the invasive capacity of papillary urothelial neoplasia [21] and is a risk factor for recurrence in patients with Dukes C colorectal cancer [22].

There are also isolated reports of the deregulated expression of individual MCMs in HCC. MCM2 is associated with the progression from cirrhosis to $\mathrm{HCC}$ and poor cellular differentiation [23, 24]. Serum MCM6 levels have been reported as the promising independent biomarker for $\mathrm{HCC}$, especially in AFP negative and small HCC patients [25]. An immunohistochemical study has shown that MCM7 is increased in HCC [26]. Silencing of MCM7 with shRNA inhibits the malignant behavior of $\mathrm{HCC}$ cells via cell cycle arrest and apoptosis [27]. However, the other members of MCMs remain poorly understood in HCC. The comparison among MCMs in HCC has not yet been performed. Hepatocarcinogenesis is a typical multistage process characterized by chronic viral infection, cirrhosis, and $\operatorname{HCC}[28,29]$. Here, we feature the expression dynamics of MCM2, MCM3, MCM4, MCM5, MCM6, MCM7, MCM8, MCM9, MCM10 and RecQ like helicase 4 (RECQL4) in the typical multistep of hepatocarcinogenesis and demonstrate the association between MCMs and clinicopathological characteristics, diagnosis and prognosis in HCC patients.

\section{Methods}

\section{Patients and samples}

The samples used in this study were categorized into three independent Cohorts. Cohort 1 was used to profile the
mRNA expression of MCMs and included 105 samples (15 normal livers, $40 \mathrm{HBV}$ cirrhotic livers and $50 \mathrm{HBV}$-related HCC). Cohort 2 consisted of 102 HBV-related HCC and matched pritumoral livers, and it was used to investigate the clinical implications of MCMs. The samples of Cohort 1 and 2 were immediately snap-frozen in liquid nitrogen after surgical excision and stored at $-80{ }^{\circ} \mathrm{C}$. The tissue microarrays HLiv-HCC1805ur-02 and HLiv-HCC1805ur03 (OUTDO BIOTECH CO., LTD, China) and part of formalin-fixed paraffin-embedded samples in our hospital were used for immunohistochemistry as Cohort 3 ( $n=$ 345 ). Cohort 3 contained various lesion types (60 normal livers, $110 \mathrm{HBV}$ cirrhotic livers, and $175 \mathrm{HCC}$ ). And the major etiology of HCC in cohort 3 were HBV but the accurate proportion was unclear. The normal hepatic samples were from the patients who underwent operation for hemangioma. A diagnosis of cirrhosis was defined histologically as having fibrosis stage 5/6 [30]. The cirrhotic livers were from $\mathrm{HCC}$-absence cirrhotic patients who underwent liver transplantation. The diagnosis of HCC was made by pathological examination of the resected tissues. Approval for these studies was obtained from the Ethics Committee of the First Hospital of Zhejiang University, and all subjects in this study provided written informed consent. All aspects of the study related to human participants were in accordance with the ethical standards of the national research committee as well as with the Helsinki declaration.

\section{Quantitative reverse transcription polymerase chain reaction}

Total RNA was isolated from tissue samples preserved at $-80{ }^{\circ} \mathrm{C}$ using Trizol (Invitrogen, USA). Good quality RNA (as confirmed by the integrity of $28 \mathrm{~S}$ and $18 \mathrm{~S}$ rRNA on agarose gel and A260/A280 ratio) was reverse transcribed by the cDNA kit (vazyme, China) according to manufacturer's protocol. Quantitative polymerase chain reaction (qPCR) assays were performed using the ABI 7500 fast system (Applied Biosystems, USA). The gene specific primers are shown in Additional file 1. Gene expression was measured in triplicate in the optimized PCR condition as described previously [31]: one cycle of denaturing at $95{ }^{\circ} \mathrm{C}$ for $3 \mathrm{~min}$, followed by 40 cycles of amplification at $95{ }^{\circ} \mathrm{C}$ for $15 \mathrm{~s}$ and $60{ }^{\circ} \mathrm{C}$ for $30 \mathrm{~s}$, and last cycle along the melting curve at $95{ }^{\circ} \mathrm{C}$ for $15 \mathrm{~s}, 60{ }^{\circ} \mathrm{C}$ for $15 \mathrm{~s}$ and $95{ }^{\circ} \mathrm{C}$ for $15 \mathrm{~s}$. Relative expression of genes was normalized to $\mathrm{GAPDH}$ and reported as $2-\triangle \mathrm{CT}$, and $\triangle \mathrm{CT}=\mathrm{Ct}$ (target gene)-Ct(GAPDH).

\section{Immunocytochemistry}

Four $\mu \mathrm{m}$ thick sections of samples were cut and mounted on poly L-lysine coated slides. Expression of the MCM2, MCM6 and MCM7 proteins were detected in paraffinembedded samples in Cohort 3. As described previously [32], the sections were de-waxed and antigen retrieval was 
performed. After blanching of endogenous peroxidase, the sections were blocked and then incubated with the primary antibody at $4{ }^{\circ} \mathrm{C}$ overnight, and subsequently washed by PBS buffer at room temperature. On the next day, the slides were incubated with the secondary antibody (Biotech Inc., China) for $60 \mathrm{~min}$ at room temperature and the DAB detection was followed by Mayer's haematoxylin nuclei counterstaining. Immunoreactivity score was assessed semi-quantitatively by determining the number of positive cells over the total number of liver cells: $0 \%, 5 \%, 10 \%$, up to $100 \%$, as reported [32, 33]. The assessment was performed by two independent pathologists in a double-blind manner. The antibodies and the dilution were detailed in the Additional file 2.

\section{Analysis of cell cycle distribution}

Human HCC cell line Huh 7 (TCHu182) was purchased from the Institute of Biochemistry and Cell Biology, Chinese Academy of S ciences (Shanghai, China) and maintained in Dulbecco's Modified Eagle's Medium supplemented with $10 \%$ fetal bovine serum (Gibco, CA, USA) in a $37{ }^{\circ} \mathrm{C}$ incubator with $5 \% \mathrm{CO}_{2}$. The cells in logarithmic growth phase were harvested, seeded into 6well plates $\left(2 \times 10^{5} /\right.$ well $)$ and transfected with Si-MCM6 or SiRNA control (Additional file 3). After $48 \mathrm{~h}$, the cells were collected for flow cytometry. This experiment was repeated three times. For the detailed methods, please refer to the previous publication [34].

\section{Statistical analysis}

Data were described as qualitative or quantitative variables. Qualitative data were compared with Fisher's exact or Pearson's chi-squared test, and quantitative ones with Student's $t$ test or Variance analysis, where appropriate. The correlations were analyzed by Kendall. Receiver operating characteristic curves (ROC) were performed to assess the diagnostic value of candidate proteins. Survival curve was plotted using Kaplan-Meier method and compared by the log-rank test. The independent factors of survival were identified using Cox's proportional hazards model. Statistical analysis was performed with SPSS version 18.0 (SPSS, Chicago, IL, USA). Two-sided P-values of $<0.05$ were considered to be significant.

\section{Results}

mRNA dynamics of MCMs in multistep hepatocarcinogenesis

The mRNA profiles of MCM2-7, MCM8, MCM9, MCM10 and RECQL4 were investigated in the Cohort 1 (normal livers, $n=15$; cirrhotic livers, $n=40$; and HCC, $n$ $=50$ ) using qPCR. As shown in Fig. 1, mRNA levels of MCM2-7, MCM8 were significantly up-regulated in HCC compared to normal or cirrhotic livers, and there was no significant difference in expression in normal versus cirrhotic livers. MCM10 was only significantly up-regulated in $\mathrm{HCC}$ relative to normal livers. However, MCM9 and RECQL4 remained unchanged throughout the process of hepatocarcinogenesis. The relative changes, medians and interquartile ranges (25th percentile to 75 th percentile) of all MCMs in each sample type were reported in Additional file 4. The top three up-regulated MCMs were MCM2, MCM6 and MCM8, which were up-regulated 4.57-, 3.11- and 2.79-fold in HCC relative to noncancerous liver, respectively. These data indicate that MCM2-7, MCM8 and MCM10 mRNA levels increase in HCC, and are candidate drivers of hepatocarcinogenesis.

\section{mRNA expression of MCM2-7, MCM8 and MCM10 in HCC and their clinical implications}

The aberrant expression of MCM2-7, MCM8 and MCM10 in mRNA levels and their clinical relevance in HCC patients were further studied in HCC and matched peritumoral livers in the Cohort $2(n=102)$. We observed the similar results as in Cohort 1, mRNA levels of MCM27, MCM8 and MCM10 all significantly up-regulated in HCC than peritumoral livers (Fig. 2a). First, we investigated the correlations between the expression levels of MCMs. As shown in Additional file 4, the mRNA expression levels of these MCMs were significantly positively correlated with each other (Kendall correlation test, $P<0.05$ ). These results indicate that the MCMs may be transcriptionally regulated together. Indeed, MCM members MCM2-7 are known to work as a complex to regulate DNA replication. Next, their clinical implications were also analyzed. As shown in Additional file 5, TNM stage correlated with MCM2-4, MCM6, MCM7 and MCM10, AFP was associated with MCM2, MCM4, MCM6 and MCM7. We proceeded to investigate whether mRNA levels of MCMs could predict the prognosis of HCC patients. Kaplan-Meier plots showed that patients with high MCM2, MCM6 and MCM7 expression had poorer outcomes $(P=0.018,0.002$, and 0.005 , respectively; Fig. 2b-d). There was no correlation between other MCM mRNA levels and patient outcome (data not shown). These results suggest that MCM2, MCM6 and MCM7 mRNA levels could be potential prognostic markers for human HCC.

\section{Protein levels of MCM2, MCM6, and MCM7 as diagnostic and prognostic indicators for $\mathrm{HCC}$}

To examine whether MCM2, MCM6 and MCM7 proteins are also exclusively overexpressed in $\mathrm{HCC}$, we analyzed their expression patterns in Cohort 3 using immunohistochemistry. We detected them with antibodies in 60 normal livers, 110 cirrhotic livers and 175 HCC. The immunoreactivities of MCM2, MCM6 and MCM7 proteins were observed primarily in the hepatocellular cell nucleus and partly in the cytoplasm (Fig. 3a). Immunohistochemistry results were concordant with qPCR expression profiles. MCM2, MCM6 

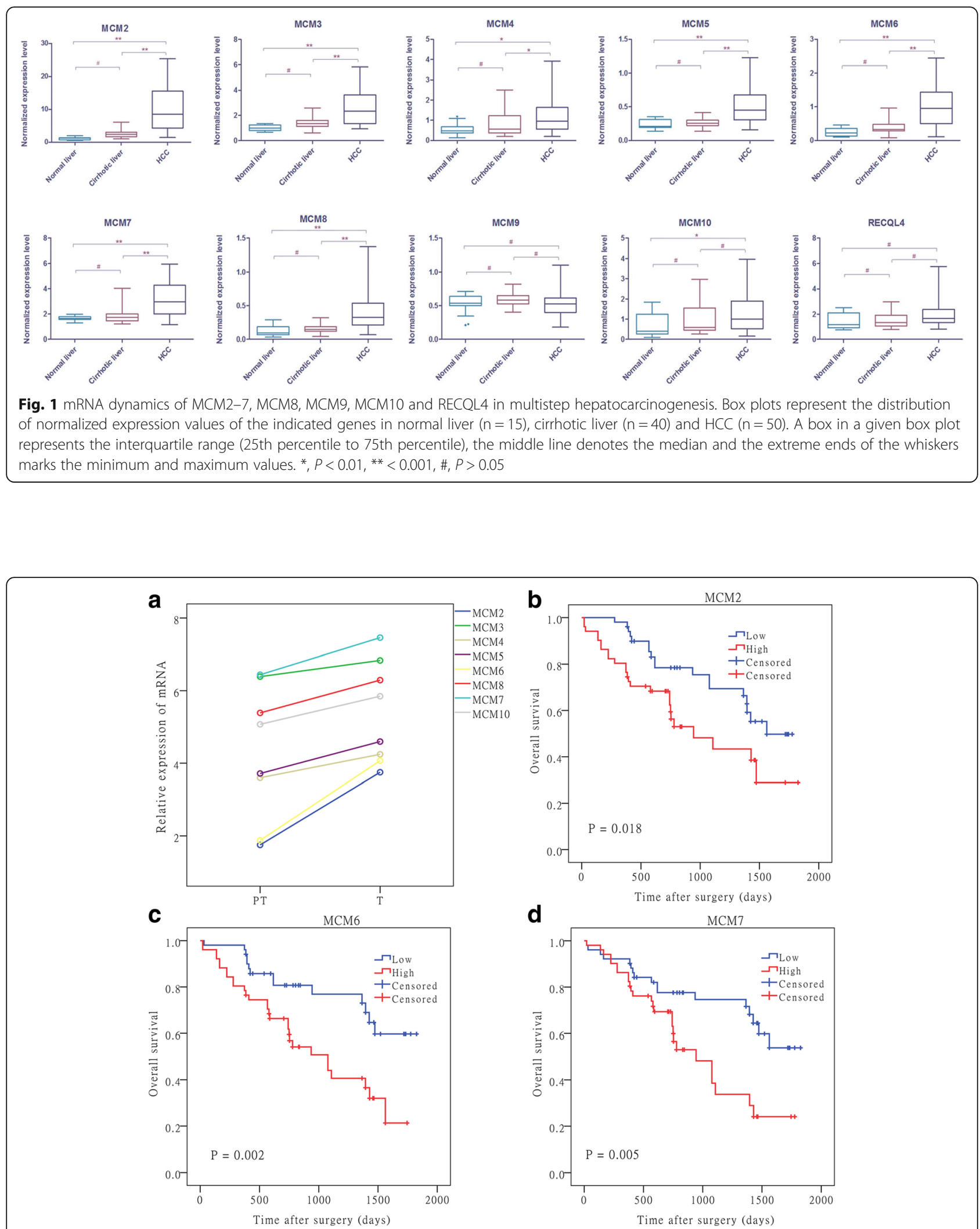

Fig. 2 Elevated MCM2-7, MCM8, MCM10 and their prognostic implications in HCC. a, MCM2-7, MCM8 and MCM10 mRNA expression levels were analyzed in $102 \mathrm{HCC}$ and matched peritumoral livers using RT-PCR and all molecules were significantly up-regulated $(P<0.01)$. N, peritumoral livers. MCM2 (b), MCM6 (c) and MCM7 (d) were associated with poor outcomes in HCC patients 


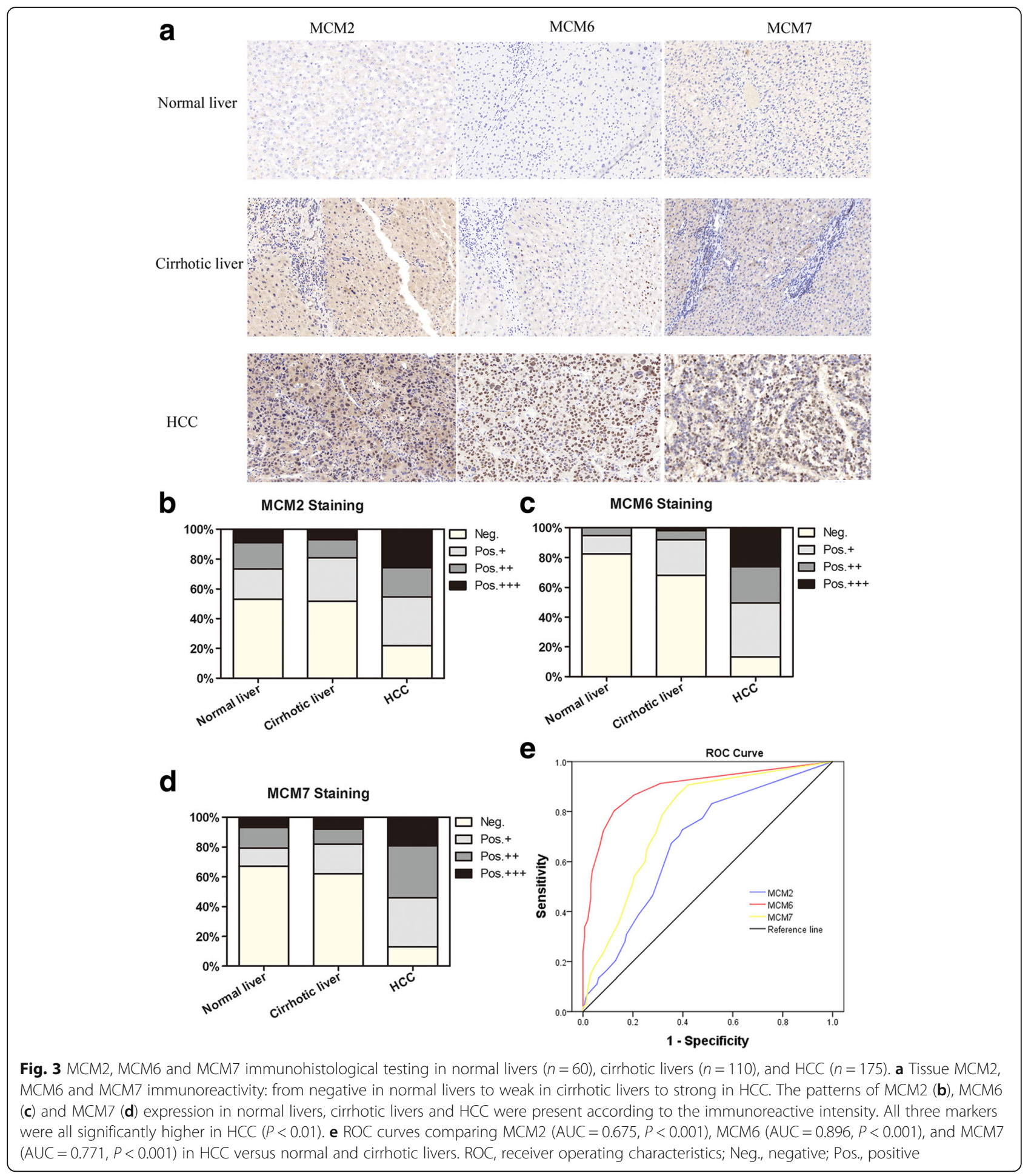

and MCM7 proteins were expressed at significantly higher levels in HCC compared to non-tumor specimens $(P<0.01$; Fig. 3b-d), and the degree of their immunoreactivity gradually increased from normal and cirrhotic livers to HCC (Fig. 3b-d). These results suggest that increased MCM2, MCM6 and MCM7 proteins are associated with human
HCC development. ROC curves were constructed to evaluate the area under the curve (AUC) for these potential diagnostic markers. The AUCs for MCM2, MCM6 and MCM7 proteins were $0.675,0.896$, and 0.771 , respectively, and all the AUCs were significant compared with a Reference Line. MCM6 demonstrated optimal diagnostic performance, with 
an AUC significantly higher than that of MCM2 and MCM7 (Fig. 3e). These data indicate that MCM2, MCM6 and MCM7 proteins are potential diagnostic tissue markers for HCC, with MCM6 protein emerging as the primary candidate.

Next, we determined the association between MCM2, MCM6, and MCM7 protein levels and specific pathologic features and outcomes in 175 HCC patients. Correlation analysis showed that MCM6 protein levels were significantly associated with Ki67 expression and differentiation, MCM7 with tumor size and Ki67 $(P<0.05$, Table 1$)$. However, no significant association between MCM2 protein levels and tumor characteristics such as tumor stage, tumor size, etc. was observed. Kaplan-Meier analysis showed that patients with high MCM2, MCM6 and MCM7 protein levels had significantly poorer prognosis than those with low expression $(P=0.020,0.001$, and
0.001, respectively; Fig. 4a-c). In addition, overexpression of multiple MCMs was found to be a very strong prognostic indictor $(P=0.001$; Fig. $4 \mathrm{~d})$, as demonstrated when MCM2, MCM6 and MCM7 were combined (threemarker panel). These results strongly suggest that the combined use of MCM2, MCM6 and MCM7 is a reliable prognostic indicator for HCC patients. Finally, further univariate and multivariate Cox regression analyses revealed that MCM6 protein is a significant and independent predictor for poor outcome in HCC patients (Table 2).

\section{Cell cycle effect of MCM6 by flow cytometry}

Because MCMs play a central role in the replication of DNA, we further studied whether the potential effects of MCM6 on the cell cycle in Huh 7 cells. Compared with control group $(54.6 \pm 5.1)$, the proportion of cells in $S$

Table 1 Relationship between MCM2, MCM6 and MCM7 expression and clinico-pathological characteristics in 175 HCC patients

\begin{tabular}{|c|c|c|c|c|c|c|c|c|c|}
\hline \multirow[b]{2}{*}{ Variables } & \multicolumn{3}{|c|}{$\mathrm{MCM}^{\mathrm{a}}$} & \multicolumn{3}{|c|}{$\mathrm{MCM}^{\mathrm{a}}$} & \multicolumn{3}{|c|}{$M C M 7^{a}$} \\
\hline & Low & High & $p$ & Low & High & $p$ & Low & High & $p$ \\
\hline Age (years) & & & 0.752 & & & 0.874 & & & 0.527 \\
\hline$\leq 50$ & 31 & 29 & & 29 & 31 & & 32 & 28 & \\
\hline$>50$ & 56 & 59 & & 58 & 57 & & 55 & 60 & \\
\hline Sex & & & 0.288 & & & 0.676 & & & 0.136 \\
\hline Female & 10 & 16 & & 14 & 12 & & 9 & 17 & \\
\hline Male & 77 & 72 & & 73 & 76 & & 78 & 71 & \\
\hline Tumor size (total diameter) & & & 0.646 & & & 0.443 & & & 0.021 \\
\hline$\leq 5 \mathrm{~cm}$ & 37 & 34 & & 38 & 33 & & 43 & 28 & \\
\hline$>5 \mathrm{~cm}$ & 50 & 54 & & 49 & 55 & & 44 & 60 & \\
\hline Tumor multiplicity & & & 0.388 & & & 0.832 & & & 0.832 \\
\hline Single & 77 & 73 & & 74 & 76 & & 74 & 76 & \\
\hline Multiple & 10 & 15 & & 13 & 12 & & 13 & 12 & \\
\hline Tissue AFP ${ }^{\dagger}$ & & & 0.880 & & & 0.228 & & & 0.451 \\
\hline Low & 44 & 43 & & 39 & 48 & & 46 & 41 & \\
\hline High & 43 & 45 & & 48 & 40 & & 41 & 47 & \\
\hline Tissue Ki67 ${ }^{\dagger}$ & & & 0.050 & & & $<0.001$ & & & 0.008 \\
\hline Low & 50 & 37 & & 62 & 25 & & 52 & 35 & \\
\hline High & 37 & 51 & & 25 & 63 & & 35 & 53 & \\
\hline Differentiation & & & 0.057 & & & $<0.001$ & & & 0.259 \\
\hline Well & 11 & 10 & & 17 & 4 & & 13 & 8 & \\
\hline Moderate & 55 & 42 & & 55 & 42 & & 50 & 47 & \\
\hline Poor & 21 & 36 & & 15 & 42 & & 24 & 33 & \\
\hline TNM stage & & & 0.742 & & & 0.324 & & & 0.103 \\
\hline I & 11 & 7 & & 8 & 10 & & 14 & 4 & \\
\hline ॥ & 37 & 37 & & 43 & 31 & & 38 & 36 & \\
\hline III & 32 & 37 & & 32 & 37 & & 31 & 38 & \\
\hline IV & 2 & 2 & & 1 & 3 & & 2 & 2 & \\
\hline
\end{tabular}

aHigh and low expression were divided by the median expression level Italic values indicate statistical significance 

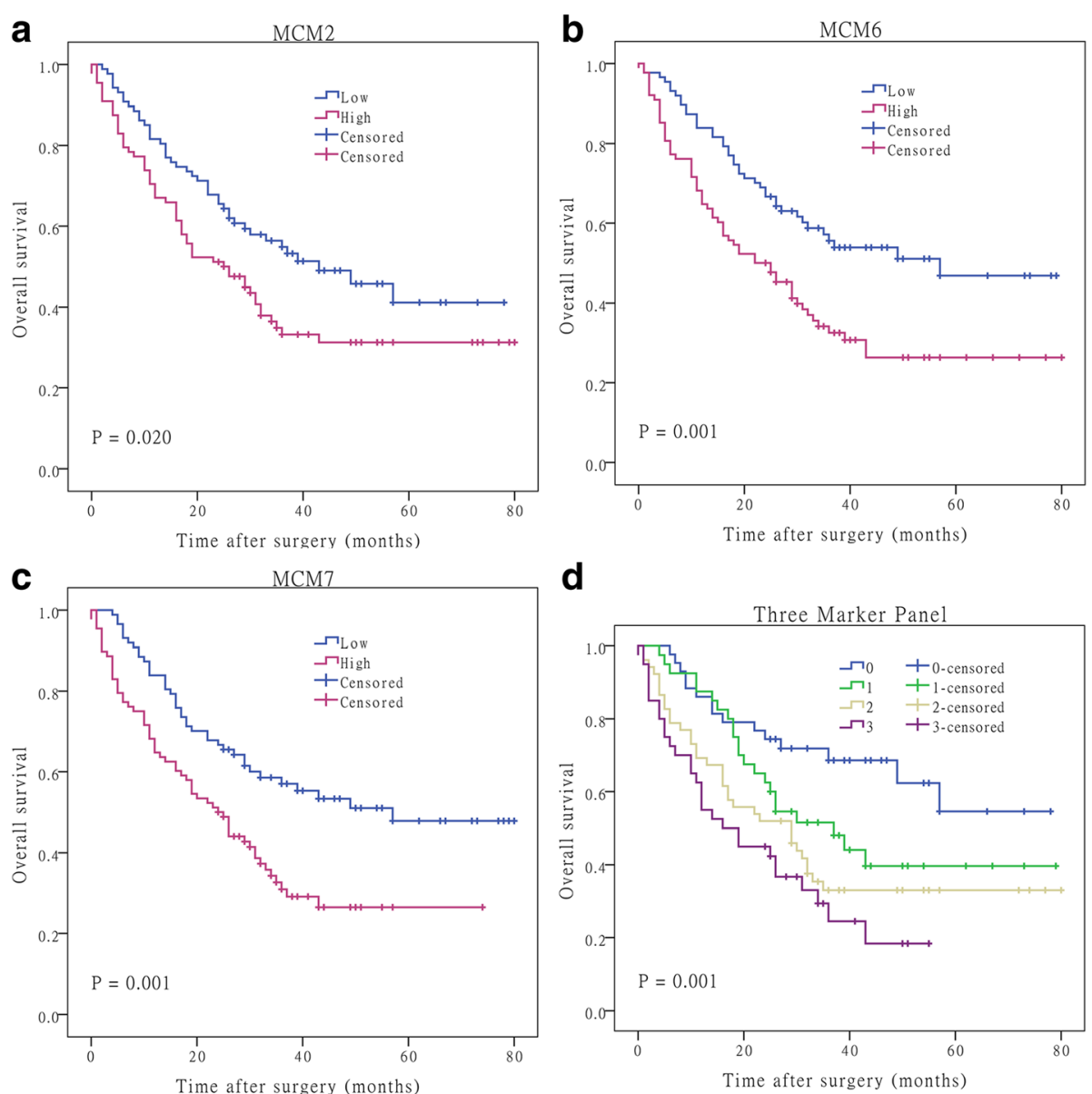

d

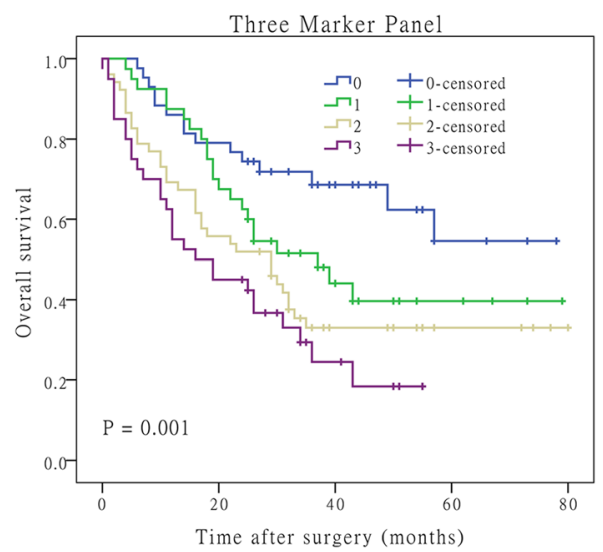

Fig. 4 Kaplan-Meier survival curves with regard to overall survival according to MCM2, MCM6 and MCM7 protein expression in 175 patients with HCC (log-rank test). Specimens were stratified into high or low expression using the median expression level as the cut-off point. Overall survival of patients with high expression of MCM2 (a), MCM6 (b) and MCM7 (c) significantly worse than that with low expression $(P=0.020,0.001$ and 0.001 , respectively). $\mathbf{d}$ Kaplan-Meier survival curve for specimens stratified into four groups based on the number of three-marker panel (MCM2, MCM6 and MCM7) expressed at a high level $(P=0.001) .0,1,2$, and 3 indicates the number of MCMs expressed at a high level

phase increased markedly $(63.6 \pm 6.0)$ while in G2 phase reduced dramatically in Si-MCM6 group (Fig. 5a and b). This suggests that cells in the Si-MCM6 group were arrested in the $S$ phase and failed to enter the G2 phase. Mechanistically, CDK2, CDK4, CyclinA, CyclinB1, CyclinD1, and CyclinE were lower in Si-MCM6 treated cells (Fig. 5c), suggesting that inhibition of MCM6 can delay the cell cycle S/G2 progression through downregulating the cell cycle checkpoint.

\section{Discussion}

Overexpression of MCMs is observed in many tumors, including cervical carcinoma [11], gliomas [13], oral squamous cell carcinoma [15, 35], and non-small cell lung carcinoma [36, 37]. In this study, we investigated the expression of MCMs in HCC via profiling their mRNA and protein levels. We further evaluated the MCMs with significantly up-regulated in HCC. Most of MCMs were showed to be up-regulated in HCC, indicating their key role in tumor cells. MCM6 were finally identified as novel candidate markers for HCC.

HCC usually occurs in the background of hepatic cirrhosis as a result of chronic hepatitis in Asia. We first presented an overview of the expression patterns of all MCMs on the spectrum of hepatocarcinogenesis. Within the MCM family, MCM2-7, MCM8 and MCM10 mRNAs were up-regulated during hepatocarcinogenesis. The increased expression of these mRNA was confirmed in Cohort 2. Interestingly, expression of certain MCMs was positively correlated with each other. It can be partial explained that MCM 2-7 form part of the prereplicative complex to promote DNA synthesis [38]. Thus, MCM proteins function to allow the DNA replication machinery to access binding sites on DNA [39]. Despite the finding that many genes in the MCM family are up-regulated in HCC, only some of them in our study exhibited a critical role in hepatocarcinogenesis. 
Table 2 Cox univariate and multivariate regression analyses of prognostic factors and MCM2, MCM6 and MCM7 expression for overall survival in HCC patients

\begin{tabular}{|c|c|c|c|c|}
\hline \multirow[t]{2}{*}{ Variables } & \multicolumn{2}{|l|}{ Univariate Analysis } & \multicolumn{2}{|l|}{ Multivariate Analysis } \\
\hline & Hazard Ratio $(95 \% \mathrm{Cl})$ & $p$ Value & Hazard Ratio $(95 \% \mathrm{Cl})$ & $p$ Value \\
\hline Age (> 50ys) & $0.89(0.59-1.35)$ & 0.590 & & \\
\hline Gender (male) & $1.24(0.69-2.23)$ & 0.464 & & \\
\hline Total tumor size (> $5 \mathrm{~cm}$ ) & $2.26(1.47-3.49)$ & $<0.001$ & $1.29(0.73-2.27)$ & 0.390 \\
\hline Tumor multiplicity (multiple) & $1.88(1.14-3.10)$ & 0.014 & $1.74(0.99-3.08)$ & 0.056 \\
\hline Differentiation (mod./ well vs poor) & $0.60(0.40-0.89)$ & 0.012 & $1.01(0.62-1.64)$ & 0.974 \\
\hline TNM stage (I-II vs III-IV) & $0.37(0.24-0.57)$ & $<0.001$ & $0.51(0.29-0.88)$ & 0.016 \\
\hline Tissue AFP (High) & $1.42(0.96-2.11)$ & 0.081 & & \\
\hline Tissue Ki67 (High) & $1.74(1.16-2.59)$ & 0.007 & $1.20(0.74-1.94)$ & 0.471 \\
\hline MCM2 (High) & $1.59(1.07-2.36)$ & 0.020 & $1.19(0.74-1.91)$ & 0.485 \\
\hline MCM6 (High) & $1.93(1.29-2.88)$ & 0.001 & $1.65(1.00-2.72)$ & 0.048 \\
\hline MCM7 (High) & $1.97(1.32-1.95)$ & 0.001 & $1.50(0.94-2.39)$ & 0.087 \\
\hline
\end{tabular}

Italic values indicate statistical significance

Our results showed that mRNA levels of MCM2, MCM6 and MCM7 were associated with certain features of tumor and the outcomes of HCC patients. Meanwhile, the overexpression of MCM4, MCM5, MCM6, MCM10 and RECQL4 mRNA has been reported as a poor prognostic indicator in cervical cancer [11]. MCM2 was demonstrated as a biomarker for esophageal [40] and bladder cancer [41]. Furthermore, the increased levels of MCMs are not only useful for the initial diagnosis but can also predict tumor recurrence.
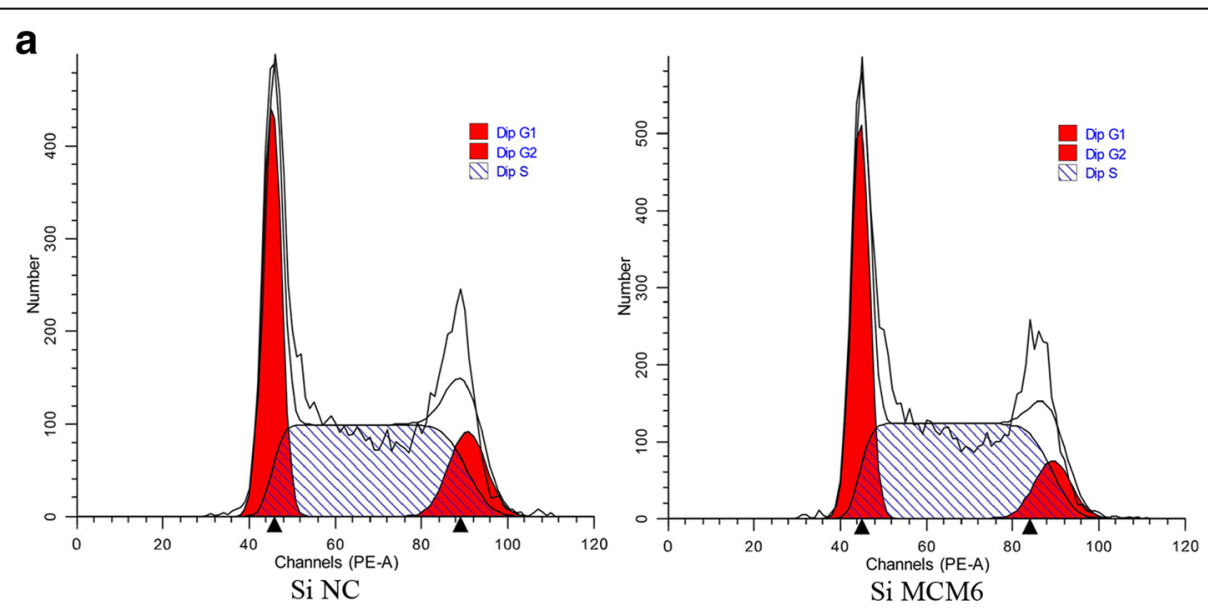

b

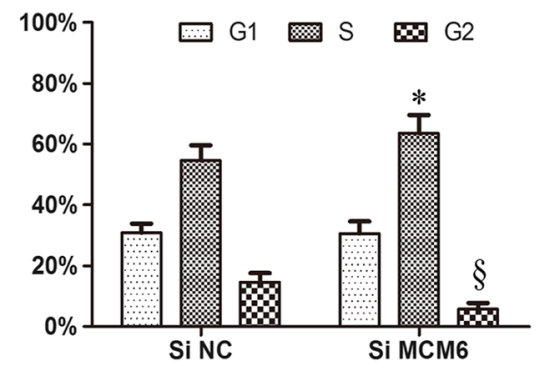

C

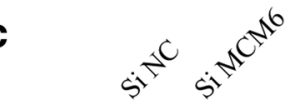

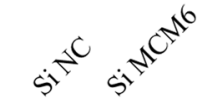

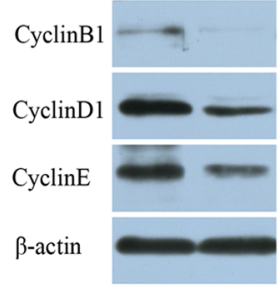

CDK2

CDK4

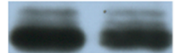

CyclinA

$\beta$-actin

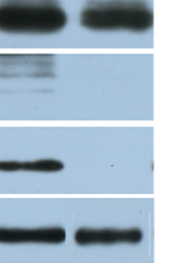

Fig. 5 Cell cycle distribution affcted by MCM6. Huh7 cells tranfected with 50 nM Si-MCM6 or negative control (Si-NC) for 48 h. a The cell cycle distribution was determined by flow cytometry in Huh7. b Histograms obtained from flow cytometry measurements show arrest in the $\mathrm{S}$ phase in cells treated with Si-MCM6. c CDK2, CDK4, CyclinA, CyclinB1, CyclinD1, and CyclinE were lower in Si-MCM6 treated cells than Si-NC. Data were expressed as the mean of 3 independent experiments. ${ }^{*}$ and§, $P<0.05$ compared to control 
We further demonstrated increased protein levels of MCM2, MCM6 and MCM7 proteins in Cohort 3 by immunohistochemistry. Little was previously known about MCM2 and MCM6 protein expression in liver cancer, we observed their up-regulation in HCC. Of three markers, MCM6 protein showed the best diagnostic performance for HCC. Importantly, increased MCM2, MCM6 and MCM7 protein levels were associated with poorer survival in HCC patients. Consistent with the report by Zhou Y et al., MCM7 protein was associated with post-operative prognosis for HCC [26]. In our study, MCM6 protein showed the best diagnostic and prognostic marker of MCMs in HCC. Recent evidence confirms even higher levels of MCM6 in plasma as a novel biomarker for HCC patients [25]. We revealed strong positive correlations in the expression of MCM6 vs. Ki67, and MCM7 vs. Ki67 in HCC samples. Thus, MCM6 could reflect high rate of proliferation in HCC cells and may serve as a potential proliferationspecific marker for HCC. Our findings not only confirm the role of MCM7 in HCC, but also identify MCM2 and MCM6 as potential tissue diagnostic and prognostic markers for HCC. However, there are some shortcomings in our study: only including HBV-related HCC which is a major etiology of HCC in China but not the only cause of HCC; using one cell lines for cell cycle effect; lacking AFP data to be analyzed and compared with MCM6. The relevance of $\mathrm{HBV}$ virus infection to the MCM expression in $\mathrm{HCC}$ with the other etiological factors such as $\mathrm{HCV}$ or fatty liver needs to be worthy of further investigation.

\section{Conclusions}

In summary, this study provides a comprehensive report of the expression profile of all MCMs in multistep hepatocarcinogenesis. The results offer an insight into the potential utility of these genes as proliferation-specific, diagnostic and prognostic markers for HCC. Further studies regarding the mechanism of MCMs in HCC may provide clues as to whether they can serve as potential therapeutic targets. Taken together, the present study has demonstrated the importance of MCM expression in HCC and that MCM6 could be a novel candidate prognostic and predictive indicator for HCC patients.

\section{Additional files}

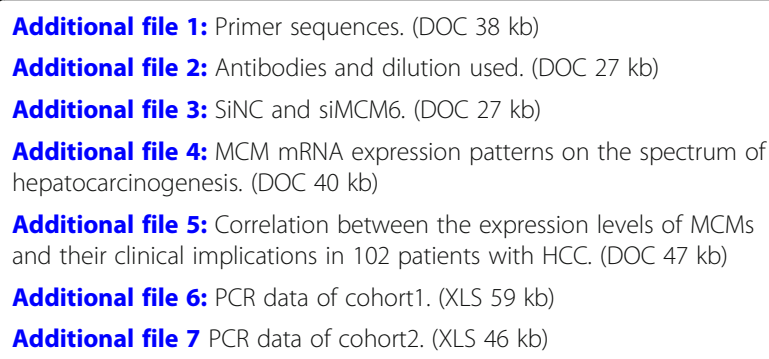

\section{Abbreviations}

AFP: alpha fetoprotein; AUC: areas under the receiver-operating characteristic curves; HBV: hepatitis B virus; HCC: hepatocellular carcinoma;

MCMs: minichromosome maintenance family; Neg.: negative; pos., positive;

PVIT: portal vein tumor thrombus; ROC: receiver operating characteristics;

Tno.: number of tumors

\section{Acknowledgements}

Thanks for the assistance in English editing provided by Russell Oliver Kosik from Medical Center, Stanford University, San Jose, California, USA.

The raw data of cohort 1 and cohort 2 refer to Additional file 6 and Additional file 7, respectively.

\section{Funding}

The study was supported in part by the National High-Tech R\&D Program of China (863 Program) (No.2012AA020204), Yangtze River scholar project, projects of medical and health technology program in Zhejiang province (2015KYB151 and 2015117734). The funding bodies had no role in the design of the study, collection, analysis, and interpretation of data and in writing of the manuscript.

\section{Availability of data and materials}

The datasets supporting the conclusions of this article are included within the article. Any request of data and material may be sent to the corresponding author.

\section{Disclosure}

The authors declare no any ethical/legal conflicts involved in the article.

\section{Authors' contributions}

$\mathrm{ZS}$ and $\mathrm{XX}$ conceived and participated in the study design, analysis and interpretation of the results. LZ, LJ, CJ, and SQ carried out experiments, helped with data analysis, and wrote the manuscript. DH, XH, and ZL supervised laboratory processes of the study and reviewed the manuscript. All authors read and approved the final manuscript.

\section{Ethics approval and consent to participate}

This study was approved by the Ethics Committee of the First Hospital of Zhejiang University in accordance with the Declaration of Helsinki, and all subjects in this study provided written informed consent.

\section{Consent for publication}

Not applicable.

\section{Competing interests}

The authors declare that they have no competing interests.

\section{Publisher's Note}

Springer Nature remains neutral with regard to jurisdictional claims in published maps and institutional affiliations.

\section{Author details}

'Division of Hepatobiliary and Pancreatic Surgery, Department of Surgery, First Affiliated Hospital, Zhejiang University School of Medicine, Hangzhou, China. ${ }^{2}$ Key Lab of Combined Multi-Organ Transplantation, Ministry of Public Health, Beijing, China. ${ }^{3}$ Collaborative innovation center for diagnosis and treatment of infectious diseases, Hangzhou, China.

Received: 26 December 2016 Accepted: 25 January 2018

Published online: 20 February 2018

\section{References}

1. Jing H, Zhang G, Meng L, Meng Q, Mo H, Tai Y. Gradually elevated expression of Gankyrin during human hepatocarcinogenesis and its clinicopathological significance. Sci Rep. 2014;4:5503.

2. Sukowati CH, Anfuso B, Croce LS, Tiribelli C. The role of multipotent cancer associated fibroblasts in hepatocarcinogenesis. BMC Cancer. 2015;15:188.

3. Torre LA, Bray F, Siegel RL, Ferlay J, Lortet-Tieulent J, Jemal A. Global cancer statistics, 2012. CA Cancer J Clin. 2015;65(2):87-108. 
4. Su L, Zhou T, Zhang Z, Zhang X, Zhi X, Li C, Wang Q, Jia C, Shi W, Yue Y, et al. Optimal staging system for predicting the prognosis of patients with hepatocellular carcinoma in China: a retrospective study. BMC Cancer. 2016;16:424.

5. Forsburg SL. Eukaryotic MCM proteins: beyond replication initiation. Microbiol Mol Biol Rev. 2004;68(1):109-31.

6. Lin DI, Aggarwal P, Diehl JA. Phosphorylation of MCM3 on Ser-112 regulates its incorporation into the MCM2-7 complex. Proc Natl Acad Sci U S A. 2008; 105(23):8079-84

7. Vijayraghavan S, Schwacha A. The eukaryotic Mcm2-7 replicative helicase. Subcell Biochem. 2012;62:113-34.

8. AlAsiri S, Basit S, Wood-Trageser MA, Yatsenko SA, Jeffries EP, Surti U, Ketterer DM, Afzal S, Ramzan K, Faiyaz-UI Haque M, et al. Exome sequencing reveals MCM8 mutation underlies ovarian failure and chromosomal instability. J Clin Investig. 2015;125(1):258-62.

9. Chang WJ, Ma LY, Lin LP, Gu LQ, Liu XK, Cai H, Yu YW, Tan XJ, Zhai YJ, Xu $X X$, et al. Identification of novel hub genes associated with liver metastasis of gastric cancer. Int J Cancer. 2009;125(12):2844-53.

10. Li NN, Zhai YL, Zhang YX, Li WQ, Yang MJ, Lei JL, Tye BK, Gao N. Structure of the eukaryotic MCM complex at 3.8 angstrom. Nature. 2015;524(7564):186-+

11. Das M, Prasad SB, Yadav SS, Govardhan HB, Pandey LK, Singh S, Pradhan S, Narayan $\mathrm{G}$. Over expression of minichromosome maintenance genes is clinically correlated to cervical carcinogenesis. PLoS One. 2013;8(7):e69607.

12. Kwok HF, Zhang SD, CM MC, Yuen HF, Ting KP, Wen Q, Khoo US, KYK C Prognostic significance of minichromosome maintenance proteins in breast cancer. Am J Cancer Res. 2015;5(1):52-71.

13. Hua C, Zhao G, Li Y, Bie L. Minichromosome maintenance (MCM) family as potential diagnostic and prognostic tumor markers for human gliomas. BMC Cancer. 2014;14:526

14. Amaro Filho SM, Nuovo GJ, Cunha CB, Ramos Pereira Lde O, Oliveira-Silva M, Russomano F, Pires A, Nicol AF. Correlation of MCM2 detection with stage and virology of cervical cancer. Int J Biol Markers. 2014;29(4):e363-71.

15. Razavi SM, Jafari M, Heidarpoor M, Khalesi S. Minichromosome maintenance-2 (MCM2) expression differentiates oral squamous cell carcinoma from pre-cancerous lesions. Malays J Pathol. 2015;37(3):253-8.

16. Jin Y, Xiong A, Zhang Z, Li S, Huang H, Yu TT, Cao X, Cheng SY. MicroRNA31 suppresses medulloblastoma cell growth by inhibiting DNA replication through minichromosome maintenance 2. Oncotarget. 2014;5(13):4821-33.

17. Zhang $X$, Teng $Y$, Yang F, Wang $M$, Hong $X$, Ye LG, Gao YN, Chen GY. MCM2 is a therapeutic target of lovastatin in human non-small cell lung carcinomas. Oncol Rep. 2015;33(5):2599-605.

18. Lameira AG, Pontes FS, Guimaraes DM, Alves AC, de Jesus AS, Pontes HA, Pinto Ddos $\mathrm{S}$ Jr. MCM3 could be a better marker than Ki-67 for evaluation of dysplastic oral lesions: an immunohistochemical study. J Oral Pathol Med. 2014;43(6):427-34.

19. Ishimi Y, Irie D. G364R mutation of MCM4 detected in human skin cancer cells affects DNA helicase activity of MCM4/6/7 complex. J Biochem. 2015; 157(6):561-9.

20. Eissa S, Matboli M, Shehata HH, Essawy NO. MicroRNA-10b and minichromosome maintenance complex component 5 gene as prognostic biomarkers in breast cancer. Tumour Biol. 2015;36(6):4487-94.

21. Guan BX, Wang XY, Yang JY, Zhou CJ, Meng Y. Minichromosome maintenance complex component 7 has an important role in the invasion of papillary urothelial neoplasia. Oncol Lett. 2015;10(2):946-50.

22. Ishibashi Y, Kinugasa T, Akagi Y, Ohchi T, Gotanda Y, Tanaka N, Fujino S, Yuge K, Kibe S, Yoshida N, et al. Minichromosome maintenance protein 7 is a risk factor for recurrence in patients with dukes $C$ colorectal cancer. Anticancer Res. 2014;34(8):4569-75.

23. Quaglia A, McStay M, Stoeber K, Loddo M, Caplin M, Fanshawe T, Williams G, Dhillon A. Novel markers of cell kinetics to evaluate progression from cirrhosis to hepatocellular carcinoma. Liver Int. 2006:26(4):424-32.

24. Sun M, Wu G, Li Y, Fu X, Huang Y, Tang R, Guo Y, Qiu M, Mao Y, Zhao F, et al. Expression profile reveals novel prognostic biomarkers in hepatocellular carcinoma. Front Biosci (Elite Ed). 2010;2:829-40

25. Zheng T, Chen M, Han S, Zhang L, Bai Y, Fang X, Ding SZ, Yang Y. Plasma minichromosome maintenance complex component 6 is a novel biomarker for hepatocellular carcinoma patients. Hepatol Res. 2014;44(13):1347-56.

26. Zhou YM, Zhang XF, Cao L, Li B, Sui CJ, Li YM, Yin ZF. MCM7 expression predicts post-operative prognosis for hepatocellular carcinoma. Liver Int. 2012;32(10):1505-9.

27. Liu J, Tian L, Chen BA, Xia JR. Biological effects of lentivirus-mediated silencing of minichromosome maintenance protein 7 with shRNA on the liver cancer MHCC-97H cells. Int J Clin Exp Med. 2015;8(6):8433-41.
28. Kim SW, Yang HG, Kang MC, Lee S, Namkoong H, Lee SW, Sung YC. KIAA1114, a full-length protein encoded by the trophinin gene, is a novel surface marker for isolating tumor-initiating cells of multiple hepatocellular carcinoma subtypes. Oncotarget. 2014;5(5):1226-40.

29. Zavattari P, Perra A, Menegon S, Kowalik MA, Petrelli A, Angioni MM, Follenzi A, Quagliata L, Ledda-Columbano GM, Terracciano L, et al. Nrf2, but not beta-catenin, mutation represents an early event in rat hepatocarcinogenesis. Hepatology. 2015;62(3):851-62.

30. Ishak K, Baptista A, Bianchi L, Callea F, De Groote J, Gudat F, Denk H, Desmet V, Korb G, MacSween RN, et al. Histological grading and staging of chronic hepatitis. J Hepatol. 1995;22(6):696-9.

31. Xu X, Liu Z, Zhou L, Xie H, Cheng J, Ling Q, Wang J, Guo H, Wei X, Zheng S. Characterization of genome-wide TFCP2 targets in hepatocellular carcinoma: implication of targets FN1 and TJP1 in metastasis. J Exp Clin Cancer Res. 2015:34:6.

32. Xu X, Liu Z, Wang J, Xie H, Li J, Cao J, Zhou L, Zheng S. Global proteomic profiling in multistep hepatocarcinogenesis and identification of PARP1 as a novel molecular marker in hepatocellular carcinoma. Oncotarget. 2016;

33. Cai MY, Tong ZT, Zheng F, Liao YJ, Wang Y, Rao HL, Chen YC, Wu QL, Liu YH, Guan XY, et al. EZH2 protein: a promising immunomarker for the detection of hepatocellular carcinomas in liver needle biopsies. Gut. 2011; 60(7):967-76.

34. Xu X, Liu Z, Wang J, Ling Q, Xie H, Guo H, Wei X, Zhou L, Zheng S. miRNA profiles in livers with different mass deficits after partial hepatectomy and miR-106b 25 cluster accelerating hepatocyte proliferation in rats. Sci Rep. 2016:6:31267.

35. Xiao X, Zhou L, Cao P, Gong H, Zhang Y. MicroRNA-93 regulates cyclin G2 expression and plays an oncogenic role in laryngeal squamous cell carcinoma. Int J Oncol. 2015;46(1):161-74.

36. Vigouroux C, Casse JM, Battaglia-Hsu SF, Brochin L, LuC A, Paris C, Lacomme S, Gueant JL, Vignaud JM, Gauchotte G. Methyl(R217)HuR and MCM6 are inversely correlated and are prognostic markers in non small cell lung carcinoma. Lung Cancer. 2015;89(2):189-96.

37. Tane S, Sakai Y, Hokka D, Okuma H, Ogawa H, Tanaka Y, Uchino K, Nishio W, Yoshimura M, Maniwa Y. Significant role of Psf3 expression in non-small-cell lung cancer. Cancer Sci. 2015;106(11):1625-34.

38. Maiorano D, Lutzmann M, Mechali M. MCM proteins and DNA replication. Curr Opin Cell Biol. 2006;18(2):130-6.

39. Laskey RA, Madine MA. A rotary pumping model for helicase function of MCM proteins at a distance from replication forks. EMBO Rep. 2003;4(1):26-30.

40. Huang B, Hu B, Su M, Tian D, Guo Y, Lian S, Liu Z, Wu X, Li Q, Zheng R, et al. Potential role of minichromosome maintenance protein 2 as a screening biomarker in esophageal cancer high-risk population in China. Hum Pathol. 2011:42(6):808-16.

41. Saeb-Parsy K, Wilson A, Scarpini C, Corcoran M, Chilcott S, McKean M, Thottakam B, Rai B, Nabi G, Rana D, et al. Diagnosis of bladder cancer by immunocytochemical detection of minichromosome maintenance protein2 in cells retrieved from urine. Br J Cancer. 2012;107(8):1384-91.

\section{Submit your next manuscript to BioMed Central and we will help you at every step:}

- We accept pre-submission inquiries

- Our selector tool helps you to find the most relevant journal

- We provide round the clock customer support

- Convenient online submission

- Thorough peer review

- Inclusion in PubMed and all major indexing services

- Maximum visibility for your research

Submit your manuscript at www.biomedcentral.com/submit
) Biomed Central 